\title{
PROPRIEDADES VALENCIAIS DE NOMES DEVERBAIS: UMA REANÁLISE DE DADOS DO PROJETO NURC COM BASE NA LINGUÍSTICA TEXTUAL E NO ESTUDO DOS ANAFÓRICOS
}

Camila De Bona

\begin{abstract}
RESUMO
Neste trabalho, revisitamos os resultados da pesquisa realizada por BONA (2011) relativa à valência de nomes deverbais em instâncias discursivas faladas. Considerando o estudo de Apothéloz e Chanet (2003) acerca dos pronomes definidos e dos pronomes demonstrativos nas nomeaçóes, traçamos novas possibilidades de classificação dos dados com base na linguística textual e no estudo das anáforas.
\end{abstract}

PALAVRAS-CHAVE: nomes deverbais; valência; pronomes demonstrativos.

\section{Introdução}

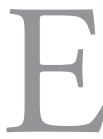

ste trabalho tem por objetivo analisar como os pronomes demonstrativos e os artigos definidos atuam em conjunto com as nomeaçóes deverbais anafóricas e a repercussão dessa ligação no que diz respeito à estruturação semântica e sintática dos complementos desses nomes. Em 2011, realizou-se uma pesquisa com o objetivo de verificar como os nomes deverbais atualizam suas valências no discurso falado, mais especificamente em textos de transcriçôes referentes aos Diálogos entre Informante e Documentador e às Elocuçôes Formais do Projeto NURC/RS, registrados em Hilgert (1997 e 2007 , respectivamente). O Projeto em questão se constitui em um arquivo de gravações de falas produzidas por falantes identificados como pertencentes à 
variedade culta da língua. A escolha por estudar nomes deverbais foi intencional, tendo em vista que o verbo é um dos elementos semanticamente mais incompletos que temos em nosso léxico e também o mais determinante, pois é ao redor dele que outras categorias de palavras irão se organizar a fim de estabelecer relaçóes de interdependência, fazendo com que ele se realize de forma plena. Nosso objetivo inicial, na época, era verificar se há um número considerável de nominalizações deverbais no corpus e, também, se os nomes deverbais preservavam nessas instâncias de fala os argumentos do verbo de que derivam ou se apresentavam uma matriz valencial mais simplificada. Após a verificação da manutenção ou não das propriedades valenciais, realizamos uma análise comparativa entre as duas instâncias discursivas supracitadas, com o fim de averiguar se a formalidade situacional era um dos fatores determinantes na atualização dos nomes deverbais no discurso falado.

Em uma descrição formal, a relação entre as estruturas semântica e sintática dos nominais pode ser formalmente previsível, mas, nas situações de uso da língua, a estruturação sintática dos nomes, no que diz respeito à sua atualização na frase, pode variar por fatores complexos: o tipo de verbo nominalizado, a extensão dos elementos que preenchem cada função semântica, a função referencial do sistema nominal, questóes de extensão de significado lexical e de formalidade do discurso. Tendo em vista que lidamos com a realização de argumentos de nomes deverbais que são, em sua grande maioria, transitivos, é importante ainda salientarmos, com Pezatti (2007), a ideia de que, enquanto a noção de transitividade tem fundamento sintático e semântico, o grau relativo de transitividade de uma sentença está fortemente vinculado a necessidades de expressão de relevância discursiva, definida em termos da relação figura/fundo no discurso narrativo.

Podemos atentar para o fato de que as nominalizaçóes, ao veicularem ideias abstratas, são indícios de uma fala mais culta e formal, justamente por serem um fenômeno mais complexo tanto em nível estrutural quanto em nível semântico, pois são morfologicamente marcadas. Ademais, muito recorrentemente, quando fazemos uso de um nome deverbal em instâncias discursivas, podemos estar retomando uma ideia já anteriormente expressa através de um verbo com seus respectivos argumentos; com isso em mente, vemos que, em muitos casos, a nominalização se atualiza já como tópico do discurso, o que pode explicar a não realização de certos argumentos. 
Este trabalho visa, em primeiro lugar, reportar alguns dos resultados da pesquisa realizada em 2011 relativamente à valência de nomes deverbais em instâncias discursivas faladas. Depois, com apoio nas consideraçóes acerca dos pronomes definidos e, principalmente, dos pronomes demonstrativos nas nomeaçôes (APOTHÉLOZ e CHANET, 2003), tencionamos traçar novas possibilidades de classificação de alguns dos dados do corpus, como uma proposta de reanálise com base na linguística textual e no estudo das anáforas.

A organização do artigo dar-se-á da seguinte maneira: primeiramente, teceremos algumas consideraçóes acerca do contexto conversacional na teoria linguística, tendo em vista estarmos tratando de textos orais; logo após, trataremos do nosso objeto de estudo, os nomes deverbais, para, depois, apresentar a teoria da valência de Borba (1996), a qual, na época, se constituiu como nosso principal referencial teórico; apresentaremos, então, nossos resultados de pesquisa e, finalmente, vamos sugerir uma proposta de reanálise de alguns de nossos dados com base em alguns preceitos da linguística textual.

\section{O contexto conversacional na teoria linguística}

O Projeto NURC (Norma Urbana Culta) e os trabalhos desenvolvidos posteriormente em decorrência dele se destinam à descrição do português brasileiro em sua manifestação falada dita culta. Este projeto se estabeleceu na década de 1970 em cinco cidades brasileiras: Recife, Salvador, Rio de Janeiro, São Paulo e Porto Alegre. Nelas, foram documentadas as falas de falantes que, por critérios claramente definidos, eram identificados como pertencentes à variedade culta da língua portuguesa, tendo-se constituído um valioso acervo de dados destinado ao estudo da língua na modalidade falada (HILGERT, 1997). O NURC é composto, basicamente, por três diferentes instâncias discursivas, quais sejam: Diálogos entre dois Informantes, Diálogos entre Informante e Documentador e Elocuçóes Formais, por meio das quais podemos identificar, nessa ordem, uma progressão crescente de formalidade e possibilidade de planejamento de fala.

Podemos apontar o fato de que o texto falado se caracteriza por ser, em sua essência, um processo antes de ser considerado um produto:

Ao contrário do escrito, o texto falado revela explicitamente toda a complexidade do processo da constituição textual, 
envolvendo tanto o planejamento verbal quanto a sua formulação linguística, determinando-se ambos numa progressiva relação de causa e efeito e sendo determinados pelas características dos interlocutores, pelas relações que os unem ou desunem e pela situação de fala. A preocupação simultânea dos falantes com o que dizer e como dizer deixa evidente, no texto falado, uma série de marcas responsáveis pela caracterização específica de sua formulação. Elas explicitam os procedimentos a que o falante se vê impelido a recorrer para levar a bom termo o seu objetivo comunicacional (HILGERT, 1997, p. 15).

Essa característica do texto falado em ser planejado e atualizado simultaneamente apresenta implicações de ordem linguística nas escolhas léxicas do falante. De acordo com nosso corpus, esse processo comunicativo se faz muito mais evidente nos Diálogos entre Informante e Documentador (DID), na instância discursiva conhecida como entrevista, já que todo ato de fala depende do que foi anteriormente proferido pelo interlocutor, não havendo possibilidade de planejamento prévio: as entrevistas presentes em nosso corpus são sobre diferentes temas, sendo realizadas diretamente entre o entrevistador e o entrevistado. Já os textos das Elocuções Formais (EF), compostos por aulas, palestras e conferências, têm a característica de serem proferidos por apenas uma pessoa, essa sendo raramente interrompida pelo público ouvinte, o que resulta na construção de uma fala baseada em um tema já estabelecido e na clara possibilidade de organizar o discurso com antecedência, assegurando a essa instância de fala um grau de formalidade relativamente maior.

É por meio dessa percepção da dinamicidade do contexto conversacional, principalmente no que atine a instâncias mais informais de fala, que se inscreve uma teoria que considera a língua como um multissistema, na qual produtos e processos coexistem (CASTILHO, 2010). Nessa recente teoria, conhecida como Gramática Funcionalista, temos, pois, a ideia de que compreender uma língua é compreender o valor comunicativo que as unidades linguísticas adquirem no sistema (MENUZZI, 2008). Ademais, temos uma maior ênfase no caráter motivado e natural das relaçóes existentes entre classes e significados, já que as formas são vistas como sensíveis ao uso e a relação entre função e gramática não é arbitrária (MACKENZIE, 1992, apud NEVES, 
1994). Partindo de uma visão funcionalista, as estruturas linguísticas não são estáticas, pois, por serem flexíveis e permeáveis às pressôes do uso, estão sujeitas a constantes reelaboraçóes.

No que tange à linguística textual, temos claro que a gramática da frase não é capaz de dar conta da gramática do texto. Com isso, Adam (2008) enfatiza a importância de uma unidade diferente de análise, partindo da frase para chegar ao texto. As retomadas de referentes têm, pois, em nível macrotextual, um propósito evidente, tendo em vista que acrescentam informaçóes complementares ao contexto e são, em muitos casos, responsáveis pela progressão da informação. Essas relações semânticas de correferência são conhecidas como anafóricas, tendo em mente que a construção de uma relação e de uma interpretação tem por intuito focalizar a ligação semântica entre duas expressões nominais definidas (ADAM, 2008). Para fins de análise, nesse trabalho, não focaremos estritamente na relação entre duas expressôes nominais, mas também entre uma expressão nominal que faz referência a uma construção constituída por um verbo e seus argumentos. Por meio de nossos dados, fica claro que o uso da nomeação deverbal, juntamente com um demonstrativo ou definido, é usado como um recurso anafórico, responsável pela progressão; essa progressão, então, ocorre não só em textos na modalidade escrita, mas também nos pertencentes à modalidade falada.

\section{Os nomes deverbais}

Um dos principais processos de formação de palavras no português é o processo derivacional de sufixação, o qual ocorre por meio da anexação de afixos à direita da base com fins de renovação lexical, tanto prosódica quanto categorialmente. Rocha (2003, p.97) afirma que a sufixação é "sem dúvida alguma, o processo de formação de palavras mais rico e diversificado da língua portuguesa, sendo, consequentemente, o mais acionado pelos falantes."

Neste trabalho, analisamos unidades léxicas conhecidas como "nomes deverbais". Essas unidades se originam do processo de nominalização a partir de verbos decorrente da sufixação, como se observa abaixo:

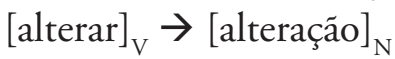

Ao anexarmos o sufixo /-ção/ no verbo alterar, temos evidente a mudança categorial operada na base através do já mencionado sufixo: do verbo 
passamos ao nome substantivo. De acordo com Rocha (2003, p.126), poderíamos entender o produto da transformação, ou o nome deverbal, como o 'ato, efeito, processo ou estado de X' (no qual $\mathrm{X}=$ verbo).

Basílio (2006, p.39) afirma que a formação de substantivos a partir de verbos apresenta três motivaçôes principais: as motivaçóes semântica, gramatical e textual. A primeira diz respeito ao uso das noçôes veiculadas pelo verbo fora da situação de predicação em uma determinada frase, o que proporciona a condição ideal para a designação genérica de eventos e demais noções verbais, o que nos possibilita falar do evento verbal sem a especificação do seu tempo ou de seu agente. A motivaçáo gramatical diz respeito ao uso do verbo em estruturas que, em termos sintáticos, exigem um substantivo; como exemplo disso, temos as nominalizaçóes em expressóes com verbo suporte: declarar $\rightarrow$ fazer uma declaração. Já a motivação textual é a mais pertinente nas colocações deste trabalho, pois diz respeito à função de anáfora que o substantivo derivado de um verbo pode assumir, para fazer referência a uma estrutura verbal já previamente utilizada no texto. Segundo Basílio (2006, p. 41), "A utilização de formas nominalizadas para substituir frases predicadas por verbos é essencial na construçâo do texto escrito, na medida em que permite representar de modo unificado e através de uma única palavra toda uma proposição [...]”.

A literatura linguística aponta para o fato de que os nomes deverbais são bastante utilizados, na língua escrita, na função de anáfora. Através de nosso corpus, foi possível verificar que os nomes deverbais, com essa função, também fazem parte da construção dos textos falados, sendo bastante utilizados neste tipo de texto. Com isso, a nominalização é de extrema importância para a continuidade do tópico na construção de textos.

De acordo com Rocha (2003), os nomes formados a partir de verbos podem designar: um indivíduo ou um objeto que é o agente de uma ação, como em pescador e alvejante, formados, respectivamente, pelos sufixos /-(d) or/ e/-nte/; um produto que indica o lugar onde se realiza a ação expressa pelo verbo, como em bebedouro e dormitório, formados, respectivamente, pelos sufixos /-(d)ouro/ e /-(t)ório/; ou, ainda, podem corresponder a um substantivo abstrato com o sentido de 'ato, efeito, ação ou estado de X': são esses últimos os substantivos que analisaremos neste trabalho, pois são esses que de fato mantêm a estrutura argumental dos verbos que lhes são correspondentes. No que diz respeito a eles, temos como exemplos os vocábulos declaração, de- 
senvolvimento, saida, preferência e lavagem, os quais correspondem, respectivamente, aos sufixos /-ção/, /-mento/, /-ida/, /-ncia/ e /-agem/. Os nomes assim formados modificam as propriedades de subcategorização inerentes aos verbos dos quais derivam. Vejamos as diferenças nas formalizações argumentais:

\section{[ALGUÉM] alterar [ALGO] $\rightarrow$ alteração [de ALGO] [por ALGUÉM]}

Vemos que tanto o verbo alterar quanto seu nome correspondente alteração são biargumentais nestes exemplos. No entanto, as valências morfossintáticas de um e de outro são diversas: se o preenchimento das casas argumentais, no que tange ao verbo, se dá através de um argumento externo (especificador do verbo) e de um interno (complemento do verbo) representados por categorias nominais, os argumentos externo e interno do nome deverbal, em uma análise formal, seriam veiculados por dois sintagmas preposicionados. No entanto, é importante salientar, segundo Camacho (2007, p.1) que "conforme o predicado verbal ganha estatuto nominal, as marcaçôes tipicamente oracionais dão lugar a outros mecanismos, como marcação argumental por preposição, modificação por adjetivo, uso de pronomes possessivos, que acompanham apropriadamente um núcleo nominal."

Através de nossos dados, podemos perceber que os argumentos que compõem a estrutura de um nome deverbal são de difícil enquadramento em uma expressão formalizada, do tipo "alteração [de ALGO] [por ALGUÉM]". Não obstante, os nomes deverbais podem ter seus argumentos expressos por anáfora zero na estrutura interna do sintagma, ou apresentar modificaçóes por meio do uso de pronomes possessivos e de adjetivos.

Camacho (2007) considera que os nomes deverbais não são nem nomes, nem verbos prototípicos, defendendo a hipótese de que, quanto mais eles preservarem a estrutura argumental, mais próximos eles estarão da referência a um estado de coisas e, portanto, mais distantes da nominalidade prototípica. Juntamente com esse autor, defendemos neste trabalho a ideia de que os nomes deverbais preservam a estrutura verbal do predicado correspondente, pois, em determinados contextos de ocorrência, há razóes funcionais para considerar que os argumentos podem estar expressos por anáfora zero, retomando termos presentes ou não na oração matriz, os quais se configuram como argumentos do nome. 


\section{A teoria da valência de Francisco Borba}

O modelo teórico adotado para a análise dos nomes deverbais neste trabalho centra-se na Teoria da Valência (BORBA, 1996). Esta teoria fornece um referencial analítico para a descrição das relaçóes de dependência que se estabelecem entre categorias que ocorrem em um contexto linguístico. Este modelo é muito conveniente para verificarmos as propriedades sintáticas e semânticas dos itens lexicais isoladamente e das construçôes sintagmáticas que eles podem originar.

A razão para a escolha de núcleos deverbais deve-se ao fato de que uma gramática de valências toma como nuclear um elemento oracional, qual seja preferencialmente o verbo, para demonstrar como os demais se dispóem em torno dele através de relaçôes de dependência. $\mathrm{O}$ verbo é um dos elementos semanticamente mais incompletos que temos em nosso léxico e, também, mais determinantes, pois é ao redor dele que outras categorias de palavras irão se dispor e estabelecer relações de interdependência. Ao nominalizarmos um verbo, ainda se mantém essa noção de incompletude no nome que é dele correspondente, ou seja, que passa pelo processo de nominalização deverbal.

Borba propóe que o termo valência deve ser utilizado em três níveis: valência lógica, valência morfossintática e valência semântica. A primeira diz respeito ao nível mais geral e abstrato, que remete ao número de argumentos que um predicado pode ter; deste ponto de vista, um item lexical pode ser avalente ou monovalente, bivalente, trivalente ou, até, tetravalente. Em se tratando da valência morfossintática, temos a caracterização dos actantes, o preenchimento das casas vazias por determinadas classes com determinadas características morfológicas; este nível trata das propriedades e funçôes sintáticas, das classes e das propriedades morfossintáticas dos itens que preenchem os argumentos ( $\mathrm{N}$, Prep + N, etc.). Já a valência semântica é deduzida da observação das regularidades ou compatibilidades das unidades que operam nas sequências; diz respeito às características categoriais ([+animado], [+comum]), às funçốes temáticas (agente, experienciador, tema) e às restrições selecionais que determinam quais classes de itens coocorrem ou se excluem com outras classes de itens.

$\mathrm{Na}$ língua comum, por exemplo, o lexema sensação, na valência lógica, é biargumental - P $(\mathrm{A})+(\mathrm{A})$; na valência morfossintática, o preenchimento 
da casa se dá com dois sintagmas preposicionados $-\mathrm{P}+\mathrm{A}$ (= Sprep.) + A (= Sprep.); já na valência semântica, o primeiro argumento (A) está marcado semanticamente com o traço [-animado] e, o segundo, com o traço [+ animado]; com isso em vista, uma possível exemplificação seria: sensação [de euforia] [pela pessoa]. Entretanto, em nosso corpus da língua comum falada, o núcleo deverbal parece apresentar propriedades valenciais diversificadas, por exemplo: no excerto "depois... sente-se uma sensaçáo de rubor no rosto... o sangue... devido ao aumento ao aumento da pressão... nessa regiāo torna mais... ativa né? então dá essa sensaçáo... depois vem a famosa tremedeira que o pessoal fala vulgarmente...", temos os nomes deverbais argumentalmente empobrecidos ao cotejarmos as ocorrências encontradas com a matriz valencial proposta por Borba.

É importante atentarmos para o fato de que os nomes, formados a partir de verbos, modificam as propriedades de subcategorização inerentes a esses verbos dos quais foram derivados. Se a ligação entre os argumentos externo (especificador) e interno (complemento) com um determinado verbo é forte, ela não se manterá na relação que um nome deverbal estabelece com seus argumentos, tendo em vista a necessidade de inserção de preposiçóes para encabeçar seus argumentos. Faz-se necessário salientarmos, no entanto, que a caracterização da valência morfossintática dos nomes deverbais atualizados no discurso é extremamente complexa, não podendo ser reduzida a construçôes formais prototípicas como 'a sensação [de algo] [por alguém]'. Apesar de haver formaçóes deste tipo, essas são raras e, podemos dizer, características de textos mais formais, principalmente os escritos, nos quais temos a possibilidade de um planejamento de estruturação sintático/semântica muito maior. Outros mecanismos de marcação argumental, como aponta Camacho (2007), tais como modificação por adjetivos e uso de pronomes possessivos, foram encontrados em nosso corpus com grande frequência.

No exemplo acima, em que há a retomada de 'sensação de rubor' por 'essa sensação', temos evidente que o demonstrativo recupera o argumento do deverbal que aparece anteriormente. Segundo Apothéloz e Chanet (2003), há a possibilidade de parafraseamento de 'essa sensação' por 'sensação disso', pois o demonstrativo é capaz de absorver os complementos, de modo que o significado do grupo nominal composto pelo demonstrativo venha a coincidir com o significado do primeiro grupo nominal. 


\section{Procedimento e análise dos dados em 2011}

O corpus da pesquisa de então se constituiu de nomes deverbais recolhidos de cinco textos de transcriçóes referentes aos Diálogos entre Informante e Documentador do Projeto NURC/RS (DID/121, DID/008, DID/009, DID/045 e DID 048) e de cinco textos referentes às Elocuçôes Formais do mesmo projeto (EF/271, EF/312, EF247, EF/289, EF299), registrados em Hilgert (1997 e 2007, respectivamente).

A metodologia de nosso trabalho consistiu na leitura atenta dos cinco textos de cada instância discursiva do NURC, especificados no parágrafo anterior, com vistas à extração das nominalizaçóes e de seus contextos de ocorrência. A confirmaçáo desses itens como nomes deverbais foi feita através de um dicionário online, intitulado Portal da Lingua Portuguesa, um repositório organizado de recursos linguísticos, o qual faz parte do ILTEC - Instituto de Linguística Teórica e Computacional. Os itens confirmados, então, foram classificados, primeiramente, de acordo com a valência de seu verbo correspondente - mono-, bi- e trivalente. Depois disso, as ocorrências foram classificadas, dentro do âmbito da valência possível do nome em questão, em função da presença ou do apagamento dos argumentos externo e interno(s). É importante deixarmos claro que consideramos a presença de alteraçóes valenciais apenas quando os argumentos dos nomes deverbais não foram passíveis de recuperação na oração matriz, o que consideramos uma motivação pragmática para o apagamento, e não semântica, de acordo com Camacho (2007). Obtivemos um total de 350 nomes deverbais e, ainda, houve casos de nominais que não foram analisados, porque o contexto não permitiu a atestação do processo morfológico.

Nossos objetivos, na época, foram:

a) Analisar nomes deverbais encontrados em textos de transcrições referentes aos Diálogos entre Informante e Documentador (Elocuçóes Semiformais) do Projeto NURC/RS e, também, os nomes deverbais encontrados em textos de transcriçôes referentes às Elocuções Formais do mesmo projeto, registrados em Hilgert (1997 e 2007, respectivamente); 
b) Comparar estes nomes deverbais presentes em diferentes instâncias discursivas da língua comum para verificar o número de ocorrências de nominalizaçóes e a preservação ou não de seus argumentos em cada instância de uso da língua.

Vejamos, agora, a sistematização de algumas das ocorrências encontradas nos Diálogos entre Informante e Documentador (DID) ${ }^{1}$, instância discursiva que apresentou a totalidade de 110 nominalizaçóes deverbais.

\begin{tabular}{|l|l|}
\hline CARACTERIZAÇÃO VALENCIAL & NOMES MONOVALENTES - EXEMPLO \\
\hline + Presença do Argumento & $\begin{array}{l}\text { “...e aumentar em outras carreiras em função } \\
\text { da inexistência de profissionais em número } \\
\text { suficiente...” p. } 50\end{array}$ \\
\hline -Presença do Argumento & $\begin{array}{l}\text { "não há problema de funcionamento agora...” } \\
\text { p. } 62\end{array}$ \\
\hline
\end{tabular}

Quadro 1: DID: Caracterização Valencial - Nomes Monovalentes

\begin{tabular}{|l|l|}
\hline CARACTERIZAÇÃO VALENCIAL & NOMES BIVALENTES - EXEMPLO \\
\hline $\begin{array}{l}\text { + Presença dos Argumentos } \\
+ \text { Argumento Externo e Interno }\end{array}$ & $\begin{array}{l}\text { “[eu] tive a sensaçáo de estar naquela pedra } \\
\text { ali...” p. } 130\end{array}$ \\
\hline+ Argumento Externo & $\begin{array}{l}\text { "sendo nosso irmão perante Deus... deveria } \\
\text { ter uma assistência ou pelo órgão do gover- } \\
\text { no que trata desse tipo de deformidade ou } \\
\text { uma clínica que trate só de pessoas deforma- } \\
\text { das..." p. } 92\end{array}$ \\
\hline+ Argumento Interno & $\begin{array}{l}\text { "sente-se uma sensaçáo de rubor no rosto...” } \\
\text { p. } 80\end{array}$ \\
\hline -Presença do Argumento & $\begin{array}{l}\text { "porque náo há essa mensuraçáo então } \\
\text { uma das causas..." p. 54 }\end{array}$ \\
\hline
\end{tabular}

Quadro 2: DID: Caracterização Valencial - Nomes Bivalentes

1 O nome deverbal analisado está em negrito e seus argumentos estão sublinhados. 


\begin{tabular}{|l|l|}
\hline CARACTERIZAÇÃO VALENCIAL & NOMES TRIVALENTES - EXEMPLO \\
\hline $\begin{array}{l}\text { +Presença dos Argumentos } \\
\text { +Presença dos Argumentos Externo e } \\
\text { Internos (2) }\end{array}$ & Nenhuma ocorrência. \\
\hline $\begin{array}{l}\text { +Presença dos Argumentos Externo e } \\
\text { Interno (1) }\end{array}$ & $\begin{array}{l}\text { “mas não não que eu tivesse uma prefe- } \\
\text { rência anteriormente pelo rádio tudo...” } \\
\text { p. } 23\end{array}$ \\
\hline +Presença do Argumento Externo & $\begin{array}{l}\text { “...eu náo tenho preferência assim por- } \\
\text { que eu gosto mais entende...” p. 26 }\end{array}$ \\
\hline +Presença dos Argumentos Internos (2) & $\begin{array}{l}\text { “...inclusive a colocaçáo dos produtos em } \\
\text { supermercados...” p. 63 }\end{array}$ \\
\hline +Presença do Argumento Interno (1) & $\begin{array}{l}\text { "problemas de colocaçáo dos forma- } \\
\text { dos...” p. 54 }\end{array}$ \\
\hline -Presença dos Argumentos & Nenhuma ocorrência. \\
\hline
\end{tabular}

Quadro 3: DID: Caracterização Valencial - Nomes Trivalentes

Agora, passemos à sistematização de algumas das ocorrências encontradas nas Elocuçóes Formais (EF), instância discursiva que apresentou a totalidade de 240 nominalizaçóes deverbais:

\begin{tabular}{|l|l|}
\hline CARACTERIZAÇÃO VALENCIAL & NOMES MONOVALENTES - EXEMPLO \\
\hline + Presença do Argumento & “a diminuiçáo da proteína...” p. 150 \\
\hline -Presença do Argumento & “lá a circulaçáo é muito mais lenta e permi- \\
te..." p. 136
\end{tabular}

Quadro 4: EF: Caracterização Valencial - Nomes Monovalentes

\begin{tabular}{|l|l|}
\hline CARACTERIZAÇÃO VALENCIAL & NOMES BIVALENTES - EXEMPLO \\
\hline $\begin{array}{l}\text { + Presença dos Argumentos } \\
\text { +Argumento Externo e Interno }\end{array}$ & $\begin{array}{l}\text { “para a nossa complementaçáo... das aulas... } \\
\text { seguintes...” p. } 87\end{array}$ \\
\hline +Argumento Externo & $\begin{array}{l}\text { “...de acordo com os conhecimentos que } \\
\text { nós já temos...” p. } 90\end{array}$ \\
\hline+ Argumento Interno & $\begin{array}{l}\text { "que vêm a ser a interpretaçáo das leis...” } \\
\text { p. } 87\end{array}$ \\
\hline -Presença do Argumento & “vimos as exemplificaçóes... e vamos...” p. 87 \\
\hline
\end{tabular}

Quadro 5: EF: Caracterizaçáo Valencial - Nomes Bivalentes 


\begin{tabular}{|l|l|}
\hline CARACTERIZAÇÃO VALENCIAL & NOMES TRIVALENTES - EXEMPLO \\
\hline $\begin{array}{l}\text { +Presença dos Argumentos } \\
\text { +Presença dos Argumentos Externo e } \\
\text { Internos (2) }\end{array}$ & Nenhuma ocorrência. \\
\hline $\begin{array}{l}\text { +Presença dos Argumentos Externo e } \\
\text { Interno (1) }\end{array}$ & Nenhuma ocorrência. \\
\hline +Presença do Argumento Externo & Nenhuma ocorrência. \\
\hline +Presença dos Argumentos Internos (2) & $\begin{array}{l}\text { “onde há formação de proteínas e colo- } \\
\text { caçáo dentro da circulação...” p. 138 }\end{array}$ \\
\hline +Presença do Argumento Interno (1) & $\begin{array}{l}\text { “...se dá absoluta preferência a pessoas } \\
\text { a líderes políticos que tiveram...” p. 119 }\end{array}$ \\
\hline -Presença dos Argumentos & $\begin{array}{l}\text { "dentre as várias recomendaçóes... uma } \\
\text { aqui é particularmente interessante...” } \\
\text { p. } 120\end{array}$ \\
\hline
\end{tabular}

Quadro 6: EF: Caracterizaçáo Valencial: Nomes Trivalentes

Através das informações demonstradas, já foi possível perceber a diferença de número de ocorrências de nomes deverbais entre as duas instâncias discursivas do Projeto NURC. Nos Diálogos entre Informante e Documentador, foram encontrados 110 nomes deverbais e, nas Elocuçóes Formais, 240, ou seja, tivemos mais que o dobro de nomes deverbais na instância discursiva considerada mais formal, como havíamos previsto no início deste trabalho. De acordo com os nossos números, então, temos claro uma maior formalidade situacional das Elocuções Formais pelo fato de seus locutores fazerem uso desse recurso linguístico muito mais frequentemente, já que as nominalizaçôes podem ser vistas como um recurso para a construção da formalidade. Como os textos analisados dessa instância linguística dizem respeito a aulas do ensino superior, corrobora-se a constatação de Basílio (2002), na qual a autora aponta que em discursos científicos podemos esperar um alto índice de ocorrência de formas nominalizadas, em oposição à língua coloquial, por exemplo.

Ao analisarmos as ocorrências separadamente, notamos que, nos nomes monovalentes, há uma maior tendência à não-realização argumental nas Elocuçóes Formais. Nossa hipótese é a de que a perda dos argumentos foi em decorrência do ambiente especializado de comunicação, ou seja, o discurso científico também pode afetar a expressão argumental desses nomes. 
O número mais expressivo de ocorrências que temos em nosso corpus diz respeito aos nomes bivalentes; de acordo com a nossa análise, percebemos que a diferença de manutenção argumental não é significativa (em torno de $5 \%$ ), o que não nos permite traçar paralelos representativos entre uma instância discursiva e outra em termos de preenchimento valencial. Em relação aos nomes trivalentes, pouco podemos atestar, devido ao fato de o número de ocorrências ter sido reduzido em nosso corpus, mas o fato de que nenhum nome manteria todos os argumentos previstos pela sua estrutura semântica já havia sido previsto, tendo em vista a pouca funcionalidade de uma construção linguística como essa.

A consideração da manutenção dos argumentos, em nossa análise, deu-se por meio de diversos mecanismos, tais como marcação por preposição, modificação por adjetivo, uso de pronomes possessivos, de orações adjetivas restritivas, etc. Se tivéssemos considerado apenas a manutenção argumental prototípica, presente na estrutura do nominal, talvez teríamos encontrado uma diferença de realização argumental significativa entre uma instância e outra, condicionada, dessa vez, não só pelo contexto de conversação, mas principalmente pela formalidade situacional, já que essa estruturação dos argumentos dentro do sintagma nominal é mais típica de instâncias de fala mais planejadas e mais formais.

Se analisarmos as propriedades valenciais de todos os nomes deverbais pertencentes às duas instâncias discursivas quantitativamente, sem atentarmos para suas peculiaridades argumentais (mono-, bi- ou trivalente) e considerarmos apenas dois níveis de análise, quais sejam [+presença de argumento] e [-presença de argumento], sendo que o nível [+presença de argumento] engloba tanto a manutenção de todos os argumentos quanto as variaçóes argumentais - apenas argumento interno, apenas argumento externo, etc. -, as porcentagens seriam as seguintes:

DID: 110 ocorrências

\begin{tabular}{|l|l|}
\hline [+presença de argumento] & [-presença de argumento] \\
\hline $79 \%$ & $21 \%$ \\
\hline
\end{tabular}

Quadro 7: DID: Análise quantitativa da manutençáo e perda dos argumentos dos nomes deverbais 
EF: 240 ocorrências

\begin{tabular}{|l|l|}
\hline [+presença de argumento] & {$[-$ presença de argumento $]$} \\
\hline $72.5 \%$ & $27.5 \%$ \\
\hline
\end{tabular}

Quadro 8: EF: Análise quantitativa da manutenção e perda dos argumentos dos nomes deverbais

Fica claro que, em termos de número de nominalizações, encontramos uma grande diferença entre uma instância discursiva e outra: temos mais do que o dobro de nominalizaçôes nas Elocuçóes Formais em comparação aos Diálogos entre Informante e Documentador. No que diz respeito à manutenção argumental, vemos que não há diferença significativa entre uma instância e outra e, de acordo com as porcentagens, temos um maior índice de manutençâo dos argumentos dos nomes deverbais nos Diálogos entre Informante e Documentador, ou seja, na instância discursiva menos formal.

\section{Novas possibilidades de classificação de alguns dados do corpus com base na linguística textual e no estudo das anáforas}

Apothéloz e Chanet (2003) apresentam um estudo acurado acerca do papel do definido e do demonstrativo nas nomeaçóes. Os autores defendem que as nomeaçóes se parecem muito com a correferência, na medida em que se tratam das mesmas informaçôes; no entanto, há uma diferença no fato de que o objeto das nomeaçóes ainda "não foi previamente estabelecido nem individuado por meio de uma expressão referencial" (p. 134). Nesse sentido, as nomeaçóes anafóricas possuem um aspecto geralmente reconhecido como de caráter resumidor, capaz de designar uma sequência mais ou menos longa de enunciaçóes.

Apothéloz e Chanet (2003, p. 170) apontam que os pronomes demonstrativos, quando determinam um substantivo predicador que designa um processo, tendem a ser sobre-interpretados e a absorver os valores dos actantes, sendo capazes de saturar os lugares dos actantes (ou complementos) do processo designado. Já os artigos definidos presentes nos sintagmas nominais geralmente retomam a base do verbo e podem vir acompanhados de complementos nominais. A sistematização disso segundo os autores seria a seguinte: 
$\rightarrow \mathrm{O}+$ substantivo predicador + complemento nominal especificando a identidade de um actante (a publicação desta obra)

$\rightarrow$ Este + substantivo predicador (esta publicação)

Vejamos, agora, como essa sistematização se faz passível de aplicação nos exemplos de nosso corpus. No que atine à questão artigo no sintagma nominal:

1. "um pessoal que fazia a distribuição por exemplo de pão chamava..." DID - p. 62

2. "você sabe as denominaçóes infantis dos dedos da mão?" DID - p. 92

3. "a aplicaçáo pelos estados e municípios do chamado Fundo de Participação...” EF - p. 114

Por meio desses dados, fica clara a retomada da base verbal por esses nomes e, consequentemente, a presença de seus complementos. Nesses casos, a manutenção dos argumentos, estando eles próximos ao núcleo nominal, é evidente.

No que diz respeito aos demonstrativos que antecedem um núcleo nominal predicador, vejamos alguns exemplos:

4. “porque não há essa mensuração então uma das causas...” DID - p. 54

5. "e sobre o aproveitamento da rede hidrográfica o senhor acha... que é bem feito esse aproveitamento?” DID - p. 133

A constatação de que o demonstrativo, quando determina um substantivo predicador que designa um processo, absorve os valores dos actantes e os satura é corroborada através dos dados mostrados acima. Além disso, segundo Apothéloz e Chanez (2003, p. 171), "é preciso não esquecer que um dos efeitos das nomeaçóes é converter em um pressuposto de existência uma informação que acabou de ser declarada". No excerto 4, esse pressuposto de existência fica claro pela primeira ocorrência de "aproveitamento", a qual apresenta o artigo definido encabeçando o sintagma nominal com a presença do argumento "da rede hidrográfica". Quando o locutor resolve retomar o nome deverbal, já não há mais necessidade de retomar também seus argumentos, e o demonstrativo "esse" é capaz de realizar essa anáfora de forma completa. Já no exemplo 5 (também presente em nosso Quadro 2, classificado como [-pre- 
sença de argumento]), não retomamos nesse recorte "o que" seria mensurado, nem "por quem" isso seria realizado; no entanto, o demonstrativo é capaz de retomar, assim como no exemplo 4, o conjunto de proposiçóes já veiculadas anteriormente na conversação.

Os exemplos 4 e 5 foram classificados em nosso estudo de 2011 como [-presença de argumentos], mas fica claro que isso deve ser revisitado, levando em conta o complexo processo de retomada anafórica realizado pelos demonstrativos. Ao invés de elucidarmos uma suposta "falta de argumentos", devemos enfatizar uma classificação que leve em conta a manutenção desses argumentos de forma diversa, através da anáfora desencadeada pelo demonstrativo. Entretanto, é importante apontarmos para o fato de que já tínhamos claro, na época, que, apesar de a relação entre as estruturas sintática e semântica em uma descrição formal ser previsível, nas situações de uso da língua, a estruturação sintática dos nomes deverbais varia por fatores complexos - principalmente por questôes de contexto conversacional (GAMARSKI, 2002). Além disso, como já relatado na seção 5 deste trabalho, já havíamos também considerado outras formas de manutenção argumental, que não somente a prototípica por preposição.

Em nosso estudo de 2011, verificou-se uma porcentagem pequena de nomes deverbais que não mantiveram seus argumentos (em torno de $20 \%$ em cada instância discursiva). Com o acréscimo dessa análise dos nomes antecedidos por demonstrativos, fica evidente que esse número deve ser, efetivamente, ainda menor.

\section{Considerações finais}

Este estudo pretendeu contribuir com a descrição das propriedades linguísticas dos nomes deverbais em situação de uso da língua, a fim de verificar suas constituiçóes sintático-semânticas. Para tanto, reportamos os resultados da pesquisa realizada em 2011 relativamente à valência de nomes deverbais em instâncias discursivas faladas, para depois, com apoio nas consideraçóes acerca dos pronomes definidos e, principalmente, dos pronomes demonstrativos nas nomeações (APOTHÉLOZ e CHANET, 2003), traçar novas possibilidades de classificação de alguns dos dados do corpus, como uma proposta de reanálise com base na linguística textual e no estudo das anáforas. 
A consideração da manutenção dos argumentos, em nossa análise de 2011, já havia se dado por meio de diversos mecanismos, tais como marcação por preposição, modificação por adjetivo, uso de pronomes possessivos e de oraçôes adjetivas restritivas, etc. Ao incluirmos, nesse trabalho, a modificação dos nominais por pronomes demonstrativos, vemos que a tendência para a manutenção dos argumentos de nomeações deverbais é bastante evidente: quando um verbo, destituído de função referencial plena, passa para um nome, esse nome passa a ter função referencial marcada no sintagma nominal, já que a manutenção de pelo menos um dos argumentos do nome deverbal se mostrou significativa já em nossa primeira análise. Além disso, quando a manutenção de argumentos não parece se efetivar, geralmente temos presente um pronome demonstrativo que é desencadeador de um complexo processo anafórico na língua, "absorvendo e saturando os actantes" (APOTHÉLOZ e CHANET, 2003). Por fim, é importante salientarmos que esse processo variado de manutenção dos argumentos é motivado pragmaticamente, levando em consideração a eficiência comunicativa em termos de relevância e economia.

\section{Referências}

ADAM, J. M. A linguistica textual: introdução à análise textual dos discursos. 2 ed. São Paulo: Cortez, 2011.

APOTHÉLOZ, D.; CHANET, C. Definido e Demonstrativo nas Nomeações. In: CAVALCANTE, M. M.; RODRIGUES, B.; CIUllA, A (orgs). Referenciação. São Paulo: Contexto, 2003.

BASÍLIO, M. Formação de classes de palavras no português do Brasil. São Paulo: Contexto, 2006

BASÍLIO, M. O Estudo da Morfologia no Português Falado: Condiçôes de Produtividade e Condiçôes de Produção. In: CASTILHO, A. (org) Gramática do Português Falado, vol. III. Campinas, SP: Editora da Unicamp, 2002.

BORBA, F. S. Uma Gramática de Valências para o Português. São Paulo: Ática, 1996.

CAMACHO, R. G. Valência do nome deverbal e nominalidade prototípica, 2007. Disponível em: <http://www.scielo.br/scielo.php?script=sci_arttext\&pi $\mathrm{d}=$ S0102-44502007000200006 > Último acesso em: 07 dez. 2011. 
CASTILHO, A. T. de. Nova gramática do português brasileiro. São Paulo: Contexto, 2010

GAMARSKI, L. Condiçôes de Estruturação Sintático-Semântica da Nominalização em Contextos Situacionais Especificos. In: CASTILHO, A. (org) Gramática do Português Falado, vol. III. Campinas, SP: Editora da Unicamp, 2002.

HILGERT, J. G. (org) A Linguagem Falada Culta na Cidade de Porto Alegre. Passo Fundo: Ediupf / Porto Alegre: Ed. Universidade UFRGS, 1997.

HILGERT, J. G. (org) A Linguagem Falada Culta na Cidade de Porto Alegre - Elocuçóes Formais. Passo Fundo: Ediupf / Porto Alegre: Ed. Universidade UFRGS, 2007.

ILTEC - Instituto de Línguística Teórica e Computacional. Disponível em: $<$ www.portaldalinguaportuguesa.org>, 25/11/2011.

MENUZZI, S. M. Funcionalismo Linguistico. Slides de curso, UFRGS, Porto Alegre, 2008.

NEVES, M. H. M. A. Gramática Funcional. São Paulo: Martins Fontes, 1997.

NEVES, M. H. M. A. Uma visão Geral da Gramática Funcional. In: ALFA, Revista de Linguística. São Paulo: Editora UNESP, 1994.

PEZZATTI, E. G. O funcionalismo em lingüistica. In: MUSSALIM F. e BENTES, A.C. (Orgs.), Introdução à Linguística: fundamentos epistemológicos. São Paulo, Cortez, 2004. 3 v. p. 165-177.

ROCHA, L.C. Estruturas Morfológicas do Português. Belo Horizonte: Editora UFMG, 2003.

SIQUEIRA, E. O Constructo de Faulstich (2003): Um Estudo dos Formativos no Léxico da Análise Sensorial Enológica. Dissertação de Mestrado. Universidade Federal do Rio Grande do Sul, Instituto de Letras, Porto Alegre, 2004. 


\title{
VALENCIAL PROPERTIES OF DEVERBAL NOUNS: A NURC DATA REANALISYS BASED ON THE TEXTUAL LINGUISTICS AND ON THE STUDY OF THE ANAPHORICS
}

\begin{abstract}
In this study, we revisit the results from the research made by BONA (2011) related to the valency of deverbal nouns in spoken discursive instances. Considering the study from Apothéloz and Chanet (2003) about the definite and demonstrative pronouns, we trace new possibilities of data classification based on the textual linguistics and on the anaphora study.
\end{abstract}

KEYWORDS: Deverbal Nouns; Valency; Demonstrative Pronouns.

Recebido em 30/03/2014

Aprovado em 25/08/2014 